Novel forms of "magical" human-computer interaction within the cyber-physical smart workplace: Implications for usability and user experience

\author{
Gladden, Matthew E. $₫$ \\ Polish Academy of Sciences, Poland (matthew.e.gladden@gmail.com)
}

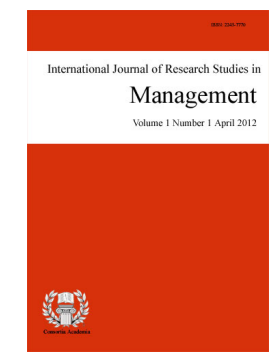

ISSN: 2243-7770

\title{
Abstract
}

The growing use of advanced AI, ambient intelligence, augmented reality (AR), and virtual reality (VR) technologies of the sort found within the emerging cyber-physical smart workplace has been described as enabling new forms of human-computer interaction (HCI) that are "magical" in nature. This study shows that from an anthropological perspective, such a workplace environment can indeed be understood as "magical"; however, that "magicality" is a double-edged sword that can potentially both enhance and damage user experience (UX) for workers and other occupants of such environments. First, by analyzing existing social anthropological and philosophical anthropological accounts of magic, typical elements of magical practice are identified. Using Nielsen's empirical analysis of HCI usability heuristics as a basis, a prospective heuristic evaluation is then carried out for the usability of a generic "magical" environment, in order to identify elements of magical practice that might be expected to enhance or impair user experience when they are required for interaction with the environment. A more specific heuristic usability evaluation is then performed for the "magical" aspects of HCI created by two kinds of constituent technologies that are typical for a cyber-physical smart workplace: those of (a) ambient intelligence and IoT-enabled systems and (b) AR and VR systems. It is shown that the magical aspects of HCI within the emerging cyber-physical smart workplace differ significantly in their potential UX impacts from the magicality involved with earlier forms of computing, and the implications of this fact for the management of future workplaces are identified and discussed.

Keywords: human-computer interaction; cyber-physical systems; smart workplaces; user experience; ambient intelligence; virtual reality; technological posthumanization; magical practice; ritual 


\section{Novel forms of "magical" human-computer interaction within the cyber-physical smart workplace: Implications for usability and user experience}

\section{Introduction}

\subsection{The context: New forms of HCI within the emerging cyber-physical smart workplace}

Ongoing rapid advances in the power and sophistication of distributed cyber-physical systems, ambient intelligence and ubiquitous computing, the Internet of Things (IoT), social and emotional robotics, and human-computer interfaces are enabling the creation of new "smart" workplace environments that almost appear to behave like sentient, living entities, insofar as they are able to detect and physically respond in real time not only to human workers' explicitly expressed task-related instructions but also to workers' more subtly manifested emotions, desires, questions, or concerns.

Within such specially designed cyber-physical smart environments, workers need not manipulate production systems or processes by spending lengthy periods of time sitting at a keyboard to manually operate complex software programs or write vast quantities of code; instead, they can interact with and control their environment in simpler and more intuitive (though simultaneously less precise) ways, through speech, gestures, or engaging with digital-physical objects in virtual or augmented reality.

A number of scholars (Renevier \& Nagy, 2001; Poupyrev, Nashida, Maruyama, Rekimoto, \& Yamaji, 2004; Sengers, Boehner, Mateas, \& Gay, 2008; Do, 2013; Rose, 2014; Fragoso \& Reis, 2016; Javornik, Rogers, Moutinho, \& Freeman, 2016; Coeckelbergh, 2018) have noted that environments incorporating such technologies appear "magical" in nature: within them, workers are able to move or reshape objects without touching them, to conjure new (digital) objects into existence out of thin air, and to transform the atmosphere or behavior of the environment simply by uttering certain words or waving their arms in a certain way. In the case of smart environments utilizing advanced brain-computer interfaces, workers might even be able to manipulate their surroundings through their thoughts alone. It is thus true that the functioning of such smart environments might appear "magical" in a loose, metaphorical sense of the word - especially to non-expert users or bystanders who are unfamiliar with the behind-the-scenes mechanics of how such smart environments work and for whom the environments represent a sort of "black-box" technology (Hynes, 2018).

\subsection{Previous analyses of the "magicality" of advanced technologies}

Such descriptions of advanced technologies as "magical" are nothing new. The relationship between advanced technologies and magic has long been explored in fictional contexts, dating back as far as Mark Twain's novel A Connecticut Yankee in King Arthur's Court (1889), in which a professional engineer from the 1880 s is transported back in time to medieval Britain, where he constructs electrical and mechanical devices whose spectacular effects are interpreted by the local population as a powerful form of magic. The conceptual link between magic and technology depicted in such tales was later summarized by Arthur C. Clarke (1973) in his famous postulate that "Any sufficiently advanced technology is indistinguishable from magic."

More formal academic study of the relationship between emerging electronic computing technologies and anthropological concepts of magic dates back at least to the 1970s. In a 1973 conference text on "Computer Magic," David Freedman (1973) drew on Bronisław Malinowski's social anthropological accounts of magical practice to analyze the "magical manipulations" that computer programmers sometimes chance upon as an elaborate, arcane, or counterintuitive means of getting a software program to perform some task in a way that cannot easily be accomplished through simpler, more straightforward, and more obvious means; if successful, 
Novel forms of "magical" human-computer interaction within the cyber-physical smart workplace

such manipulations may "become ritualized and are passed on from one programming generation to the next." More recent texts (Gell, 1992; S. Collins, 2004; Friedman, 2009; Howard, 2014; Ouellet, Romero, \& Sawchuk, 2017; McCarthy \& Wright, 2018; Pataranutaporn \& Lyle, 2018) have considered further aspects of the relationship between computer programming and magic within diverse contexts.

\subsection{The need to develop a clearer understanding of the "magicality" of magical HCI}

Many recent studies tend to focus on the positive aspects of "magical" human-computer interaction (HCI), as though "magical" HCI were synonymous with an amazing, enjoyable, effortless, sublimely productive user experience. In this study, however, it is argued that scholarly analyses that describe such emerging technologies with uncritical approval as a form of "contemporary magic" - as though any "magical" characteristics found within a given environment were necessarily associated with improved usability, enhanced user experience (UX), and positive technological progress - are grounded in an understanding of "magic" that diverges significantly from established academic approaches to the definition and analysis of magical practice that have been developed over many decades within fields like social and philosophical anthropology. It is not the aim of this study to suggest that scholars in the field of human-computer interaction should not develop their own unique understanding of the concept of "magic" as it relates to HCI. (And, indeed, scholars in fields like theology maintain their own definitions of "magic" that differ significantly from those found in anthropology, while in the fields of neuroscience and psychology the concept of "magical thinking" has yet another definition (Keinan, 1994; Zusne \& Jones, 2014).) It is, however, argued here that attempts within the field of HCI to define, describe, or analyze the emerging cyber-physical smart workplace as a "magical" environment would be strengthened and improved if they were informed by a systematic understanding of concepts of magic drawn from anthropology especially insofar as that field offers rich and nuanced accounts of magical practice that suggest that any technological environment that is maximally "magical" would necessarily involve some elements of HCI that are highly desirable (i.e., from the perspective of UX), while simultaneously involving other forms of HCI that are highly undesirable.

\subsection{Research objectives and outcomes}

It is hoped that this study can serve as a meaningful elaboration of, complement to, or alternative to existing discussions of the magicality of cyber-physical smart workplaces in at least three ways:

$>\quad$ This work shows that from the perspectives of social and philosophical anthropology, HCI in cyber-physical smart workplaces is not simply "magical" in an informal or metaphorical sense; rather, it can be analyzed as a form of true magical practice that is arguably just as "magical" as other historical cultural practices studied within those fields. This can facilitate the incorporation of existing insights from anthropology directly into HCI design for cyber-physical smart workplaces.

$>\quad$ This study demonstrates that "magicality" in HCI is not a quality that should be unreservedly pursued when designing a cyber-physical smart workplace: magicality cannot be identified simply or directly with the creation of a "user-friendly" or "user-unfriendly" environment; rather, magicality is a double-edged sword that encompasses a complex mix of characteristics that are partially advantageous and partially disadvantageous from the perspective of usability and HCI user experience.

$>\quad$ This study identifies and analyzes ways in which the magicality of "classical" forms of computer programming and software use (i.e., those that became widespread beginning in the 1970s) differs significantly from the magicality of HCI present within the emerging cyber-physical smart workplace. This provides a meaningful update to Freedman's research from the 1970s and offers novel empirical insights into the way in which the "magical" qualities of HCI have evolved over recent decades.

These findings can provide developers of cyber-physical smart workplaces with new conceptual approaches that they can draw on when designing new work environments, analyzing the functioning of existing workplaces, 
Gladden, M. E.

and discussing the desired or actual performance characteristics of cyber-physical smart workplaces with non-expert clients and other stakeholders.

\section{Methodology}

\subsection{Research approach}

According to the classification frameworks for research methodologies presented by Wilson (2010), this study employs an inductive approach, qualitative methodology, and phenomenologically based research philosophy. Its understanding of the relationship between human beings and their environment and of the nature of causal interaction is informed especially by the systems-theoretical philosophical anthropology developed by the Polish phenomenologist Roman Ingarden (1960, 1961, 1970, 1974), which offers conceptual tools that are useful for analyzing human interaction with emerging posthumanizing technologies like those relating to the cyber-physical smart workplace (Gladden, 2018a, 2018b).

The study has relied on the collection, analysis, and synthesis of secondary data in the form of published scholarly texts; data-collection utilized a cross-sectional time horizon and non-probability sampling methods. Purposive sampling was employed by performing keyword searches in online scholarly databases to identify articles addressing relevant aspects of human-computer interaction, cyber-physical systems, and magic, with priority given to particularly influential (e.g., frequently cited) texts and recent scholarship. When identifying and analyzing texts that proposed or investigated theories of magic, priority was given to works employing social anthropological or philosophical anthropological perspectives. Eliminated from the pool of secondary data were texts in which the term "magic" or "magical" was used in non-relevant senses (e.g., referring to prestidigitation and "magic tricks" performed as stage entertainment). As a form of snowball sampling, the bibliographies of gathered works were then used to identify additional potentially relevant works. In total, more than 130 scholarly texts were identified as targets for analysis; particular works within that collection of secondary data whose analysis yielded relevant information and insights are cited in the Results and Discussion sections below.

\subsection{Structure of the study}

Execution of the study involved several steps, which are reflected in the structure of the text. First, by analyzing and synthesizing existing literature relating to social anthropological and philosophical anthropological accounts of magical practice, typical elements of magical practice were identified. Those elements were then grouped according to their relevance to particular spheres of HCI, employing the categorization scheme contained in the "activity checklist" for HCI evaluation developed by Kaptelinin, Nardi, and Macaulay (1999). Using the empirical analysis of HCI usability heuristics conducted by Nielsen (1994) as a basis, a prospective heuristic evaluation was then carried out for the usability of a generic "magical" environment, in order to identify particular elements of magical practice that can be expected to enhance or impair UX, if they are required for interaction with that environment. Finally, typical characteristics of the emerging cyber-physical smart workplace were identified, and a more specific prospective heuristic usability evaluation was performed for "magical" aspects of HCI involving two kinds of constituent technologies typical for such a workplace: (a) ambiently intelligent and IoT-enabled systems and (b) augmented and virtual reality systems. As is explained in more detail in Sections 3.4 and 3.5, such heuristic usability evaluations are carried out for a given system by conceptually breaking down the system's structures and behaviors into constituent components and then assessing whether the descriptions of those structures and behaviors include elements that exemplify (i.e., are consistent with) or violate (i.e., are inconsistent with) a given set of heuristic principles that have been found to enhance usability and user experience when manifested by a technological system. (Thus, a software program that instantly shuts itself down - and erases all of the work that was in progress - if a user accidentally presses a certain combination of keys on the keyboard violates the heuristic principle that "A user 
should be asked for confirmation before a system undertakes any action that irrevocably destroys the user's work in progress" (Holcomb \& Tharp, 1991; Apple Computer, 1992; Nielsen, 1994; Nasoz, Bryce, Palmer, \& Rugg, 2011).)

\section{Results}

\subsection{Identification of typical elements of magical practice: An anthropological perspective}

Well-known social anthropological, philosophical anthropological, and sociological approaches to defining magic include the "Law of Similarity" and "Law of Contagion" found in Frazer's influential (though increasingly outdated) historical and evolutionary account of sympathetic magic (Frazer, 2009); the functional and sociological approaches of Hubert and Mauss (1902) and Durkheim (1995), according to which magic is an anti-social practice conducted by the individual in secret to achieve some personal ends; and the functionalist and social anthropological approach of Malinowski (1966, 2005), according to which every human being uses both "scientific" and "magical" ways of thinking, in different circumstances - with both magic and science constituting efforts to organize our knowledge of the natural world with the goal of better understanding, predicting, and influencing its workings.

In Malinowski's formulation, science emerges from our experience with technical skills (like gardening or architecture), while magic emerges from our emotional need to grasp and explain those frustrating and disappointing cases in which our technical skills do not yield the desired results. For Malinowski, particular types of symbolic and spoken language are critical to magical practice: ritual magical language is not a language for everyday use; rather it possesses a high "coefficient of weirdness" (Malinowski, 1966) that facilitates in its practitioners the belief that the magic might somehow inexplicably achieve their desired ends. More recently, Tambiah $(1973,1990)$ has developed further social anthropological accounts of the nature of magical language and incantations and of the distinct types of "rationality" found in magical, scientific, and religious practice. Other recent systematic analyses of magical practice include Sørensen's (2007) cognitive approach and Greenwood's (2009) anthropological approach.

By analyzing and synthesizing such studies of the phenomenon of magic, it was possible to identify 14 elements that are common to magical practice and "magical" means of attempting to interact with and manipulate one's environment, as they have existed in diverse times, places, and cultures throughout human history. A given body of cultural practice need not incorporate all (or even most) of the 14 elements in order to be considered "magical" in nature; however, a practice recognized as magical will generally involve a significant number of these elements, and the more elements are present, the more "magical" the practice will appear. These typical elements of magical practice are described below.

Reliance on invisible copy-original links - Magical practice frequently relies on mimesis and supposed invisible causal links that exist between an original object and its copy or representation; such dynamics provide the rationale for sympathetic magic that is believed by its practitioners to be capable of operating at a distance (Frazer, 2009; Sørensen, 2007; Nuño, 2014; Bubandt \& Willerslev, 2015; Rhodes \& Pitsis, 2008).

Harnessing of invisible agents or forces - Magical practitioners frequently attempt to manipulate their environment by (a) channeling or controlling invisible forces that are capable of generating some desired effects within the world or (b) summoning and commanding invisible supernatural agents that are believed to be capable of performing within the world certain types of actions that the human practitioners cannot directly or easily perform themselves (Sørensen, 2007; D. Collins, 2003; Sperber, 2004; Philsooph, 1971; Adams, Olsen, \& M.A. Smith, 2013; Brottman, 2009; Manning, 2014; Stein \& Stein, 2017).

Manipulation of complex, non-intuitive dynamics of “occult” causality - Magical practice supposes practitioners' ability to understand and manipulate causal mechanisms that are "hidden" or "occult" (from the 
Latin "occulere," meaning "to conceal"). Such forms of causality differ from the laws of nature as generally understood and are unknown to most people (Frazer, 2009; Tambiah, 1973; D. Collins, 2003; Eleta, 1997; Hagen, 2017; Stein \& Stein, 2017).

Use of specially prepared ritual implements - Magical practice employs specially prepared ritual instruments that are supposed to be capable of generating some magical effect that exceeds what the items can produce through their naturally inherent physical properties (Hagen, 2017; Greenwood, 2009; Dieleman, 2011; J.Z. Smith, 1995).

Use of specially prepared ritual clothing - Magical practitioners wear specially prepared ritual clothing that is supposed to be capable of generating some unusual effect and that serves a role other than that of simple protection, modesty, or adornment (Schwarz, 1979; Morgan, 2018; Randles, 2013; Mohan, 2017).

Reliance on powers that function only within ritual contexts - Magical practice involves attempts to cultivate and exercise powers that only function within particular ritual contexts: for example, magical speech or gestures are expected by practitioners to generate some desired effect if used within an appropriate ritual setting but are devoid of any effect if used outside of that context (Sørensen, 2007; Greenwood, 2009; D. Collins, 2003; Mirelman, 2018).

Arcane and asocial symbolic languages - Specialized types of symbolic language are critical to magical practice (Malinowski, 1966; Tambiah, 1968, 1973; Sørensen, 2007; Dąbrowska, 2010; Hagen, 2017). Such ritual magical language is not a language for everyday use but instead possesses a high coefficient of weirdness (Malinowski, 1966). Such magical language employs an arcane grammar, vocabulary, and body of literary forms that are only understood by a small group of initiated practitioners.

Arcane and asocial gestures - Magical practice similarly involves the use of physical movements and gestures possessing a high coefficient of weirdness; such exotic and unnatural movements are not part of practitioners' everyday behavior and their meaning is not obvious to the uninitiated (Malinowski, 1966; Hagen, 2017; Morris \& Peatfield, 2002).

Use of lengthy, complex incantations - Magical practice frequently involves the use of lengthy, complex ritual scripts that require arranging strings of spoken words or sounds or written text or symbols in a pattern governed by esoteric laws; even a slight error in the creation or execution of the script may be believed to render the entire incantation ineffective (Malinowski, 1966; Tambiah, 1968, 1973; Senft, 1997; Klaniczay, 2013; Hagen, 2017; Sørensen, 2007).

Use of magic words - Magical practice may involve the use of individual "magic words" or "power words," which are, in a sense, the opposite of lengthy and complex incantations: a magic word is a single syllable, word, or brief phrase that is believed to immediately generate some unusual effect within the world, when uttered; it does not need to be incorporated into a long and elaborate ritual script (Stoller, 1984; Wallis, 2002).

Emotion-driven techniques for interaction - Magical practice is driven largely by emotional dynamics rather than logical and reasonable intentions or methodologies (Malinowski, 2005; Nadel, 2013; Sørensen, 2007; Subbotsky, 2011). For example, contemporary scientifically grounded medical approaches to treating illnesses and saving lives are generally applied dispassionately by professionals as a practical technical skill and with a rational expectation of success; magical approaches, on the other hand, are driven largely by the emotional needs of practitioners and their communities and openly manifest such emotional characteristics.

Required mastery of an esoteric body of knowledge - Magical practice requires practitioners to learn (often by heart) a vast body of esoteric knowledge and techniques with which members of the general public are unfamiliar (Sørensen, 2007; Hagen, 2017; Hanegraaff, 2003; Eleta, 1997). Acquiring mastery of such knowledge may require years of study and practice. 
Rules developed and policed by an initiated elite - Magical practice is often performed according to a complex set of rules and conventions that are formulated and policed by a small group of elite practitioners. Membership in the initiated magical elite is not open to the general public; current initiates often exercise exclusive responsibility for selecting and training their successors (Sørensen, 2007; Hagen, 2017; Eleta, 1997).

Accessing of non-natural worlds - Magical practice is believed by its practitioners to grant access to parallel or supernatural spheres of reality that are not visible to, accessible to, or manipulable by ordinary inhabitants of the everyday natural world (Sørensen, 2007; Davila, 2002; Enzheng, 2002; Dąbrowska, 2010; Stein \& Stein, 2017).

\subsection{Correlating elements of magical practice with different spheres of HCI}

For purposes of this study, it was desirable to arrange the 14 elements of magical practice described above into a number of coherent categories that are relevant from the perspective of human-computer interaction. This was accomplished by employing the "activity checklist" tool developed by Kaptelinin et al. (1999) for use in the design and evaluation of $\mathrm{HCI}$ within a particular environmental context. Their tool categorizes interaction-relevant phenomena into the four spheres of: (1) "Means/ends," which encompasses goal orientation and the hierarchical ways in which activities performed at one scale causally impact higher-order or lower-order activities; (2) "Environment," which includes particular objects, devices, and technologies and users' orientation toward such tools; (3) "Learning/cognition/articulation," which encompasses the ways in which users recognize, learn, and internalize the dynamics at work within the environment and, in turn, express and externalize their desired outcomes by manipulating the environment in a way meant to generate particular desired outcomes; and (4) "Development," which encompasses ways in which a user's environment undergoes structural transformation as a result of the user's activities within and interaction with it.

In the case of a cyber-physical smart workplace that offers its occupants "magical" ways of interacting with it, it is possible to understand each magical element of that interaction as falling within one of the four spheres described by Kaptelinin et al. (1999). For example, the element of "Use of specially prepared ritual implements" relates to the HCI sphere of the "Environment," insofar as it involves particular types of physical objects. The "Manipulation of complex, non-intuitive dynamics of 'occult' causality" performed by users of magical environments relates to the HCI sphere of "Means/ends," insofar as it involves the causal mechanisms by which users hope to bring about certain desired ends within their environment. Meanwhile, the magical environment's ability to enable the "Accessing of non-natural worlds" can be understood as relating to the HCI sphere of "Development," insofar as it functionally or virtually transports users out of their everyday world and into a new interactive cyber-physical world with its own unique structures and dynamics. Figure 1 presents the elements of magical practice that may be active in a generic magical environment, as categorized according to the four spheres of HCI identified by Kaptelinin et al. (1999).

As Figure 1 indicates, the magicality of a given environment has the potential to manifest itself in all four spheres that define the ways in which users interact with that environment; the greatest number of potentially magical aspects is found in the sphere of "Learning/cognition/articulation" and the least in that of "Development."

\subsection{Developing a basis for the prospective heuristic evaluation of the usability of "magical" cyber-physical smart workplaces}

One of the more widely-cited and influential (Rogers, 2004; Quiñones \& Rusu, 2017; Da Silva de Queiroz Pierre, 2015) approaches to creating a systematic inventory of elements that contribute to the creation of successful HCI is that of the usability heuristics developed by Nielsen and Molich (Molich \& Nielsen, 1990; Nielsen \& Molich, 1990) and later elaborated and tested by Nielsen (1994) as part of a comparison with other suggested approaches. From among 101 usability heuristics previously proposed by various scholars, Nielsen's 
empirical study identified 16 heuristics that played the greatest role in explaining either (a) the most serious usability problems or (b) all of the usability problems recorded in a database of usability problems gathered from earlier projects (Nielsen, 1994). In general, systems for human-computer interaction that operate in accordance with those 16 heuristics will possess few (and few serious) usability problems, while those systems for HCI that violate all of those heuristics will typically possess many (and severe) usability problems.

\section{Anthropological characteristics of a generic magical environment \\ (as categorized according to the four spheres of $\mathrm{HCl}$ described by Kaptelinin et al.)}

\section{Type of magical practice employed by users with the goal of interacting with the environment}

\section{Corresponding \\ sphere of human-computer interaction}

\section{Reliance on invisible copy-original links}

Harnessing of invisible agents or forces

Manipulation of complex, non-intuitive dynamics of "occult" causality
Magical practice relies on mimesis and supposed invisible causal links between an original object and its copy or representation; such dynamics provide the rationale for sympathetic magic that is believed capable of operating at a distance

Magical practitioners attempt to manipulate their environment by controlling invisible forces or commanding invisible agents that are believed capable of effecting within the environment some results that the practitioners cannot directly achieve themselves

Magical practice supposes practitioners' ability to understand and manipulate causal mechanisms that are "hidden" or "occult"; such forms of causality differ from the laws of nature as generally understood and are unknown to most people

\section{Use of specially prepared ritual implements}

Use of specially prepared ritual clothing

Reliance on powers that function only within ritual contexts

Arcane and asocial symbolic languages Arcane and asocial gestures

Use of lengthy, complex incantations

Use of magic words

Emotion-driven Emotion-drive techniques
interaction

Required mastery of an esoteric body of knowledge

Rules developed and policed by an initiated elite
Magical practice employs specially prepared ritual instruments that are supposed capable of generating some magical effect that exceeds what the items can produce through their naturally inherent physical properties

Magical practitioners wear specially prepared ritual clothing that is supposed capable of generating some unusual effect and that serves a role other than that of simple protection, modesty, or adornment

Magical practice involves actions (e.g., magical speech or gestures) that are believed to generate some effect if used within an appropriate ritual setting but are ineffective outside of that context
Environment

Magical practice involves specialized symbolic languages not meant for everyday use such "weird" magical language employs an arcane grammar, vocabulary, and body of literary forms understood only by initiated practitioners

Magical practice involves physical gestures possessing a high "coefficient of weirdness"; such exotic and unnatural movements are not part of practitioners' everyday behavior and their meaning is not obvious to the uninitiated

Magical practice employs lengthy, complex ritual scripts that involve arranging strings of spoken words or symbols in a pattern governed by esoteric laws; even a slight error invalidates the entire script

Magical practice may involve the use of individual "magic words"; such a word is believed to immediately generate some unusual effect within the environment and need not be incorporated into a lengthy ritual script

Magical practice is driven largely by emotional dynamics rather than logical and reasonable intentions or methodologies; magic is generally not applied dispassionately by professionals as a practical technical skill with a rational expectation of success but is instead motivated by emotional needs

Magical practice requires practitioners to learn (often by heart) a vast body of esoteric knowledge and techniques with which members of the general public are unfamiliar, acquiring such knowledge may require years of study and practice

Magical practice is performed according to a complex set of rules and conventions that are formulated and policed by a small group of elite practitioners; current initiates often exercise exclusive responsibility for selecting and training their successors
Learning / cognition / articulation

Means/ends

Accessing of non-natural worlds

Magical practice is believed to grant practitioners access to parallel or supernatura spheres of reality that are not visible to, accessible to, or manipulable by ordinary inhabitants of the everyday natural world

\section{Development}

Figure 1. Characteristics of magical practice within a generic magical environment, as categorized according to their proposed relationship with the four spheres of HCI identified by Kaptelinin et al. (Source: author's own design.)

Some - but not all - of those usability heuristics are relevant to magical practice, insofar as certain elements 
of magical practice inherently conflict with or embody such heuristics. By performing a conceptual analysis of the most impactful heuristics identified by Nielsen and comparing the heuristics with the 14 typical elements of magical practice, it was possible to select 11 heuristics for the creation of successful HCI that may be either exemplified or violated by one or more of the elements of magical practice. These 11 heuristics (in alphabetical order) were:

$>\quad$ "Aesthetic integrity, keep design simple": a system's graphical interface should be simple but should avoid using overly simplistic, arbitrary images whose meaning is not clear to a novice user (Nielsen, 1994; Apple Computer, 1992).

$>$ "Consistency: same thing looks the same": the same (digital) object should always manifest itself in the same visible form (Nielsen, 1994; Apple Computer, 1992).

> "Easy to discriminate action alternatives": a user should be able to easily distinguish all available actions and their effects (Nielsen, 1994; Polson \& Lewis, 1990).

$>\quad$ "Familiar user's conceptual model": the system should employ analogies to familiar concrete objects (Nielsen, 1994; D.C. Smith, Irby, Kimball, Verplank, \& Harslem, 1982).

> "Feedback timely and accurate": a user should not need to wait to learn whether input has been accepted and what its result will be (Nielsen, 1994; Rohn, 1993).

$>\quad$ "Modeless interaction": the results generated by a given action should always be the same, rather than depending on which hidden state or mode the system is currently operating in (Nielsen, 1994; D.C. Smith et al., 1982).

$>\quad$ "Real-world conventions": a system should follow existing conventions in widespread use in the real world, rather than replacing them with its own idiosyncratic practices (Nielsen, 1994; Rohn, 1993).

> "Salient repertoire of available actions": all possible relevant actions (and only relevant actions) should be displayed to the user (Nielsen, 1994; Polson \& Lewis, 1990).

$>$ "Seeing/pointing vs. remembering/typing": actions should be performed by manipulating already-visible objects (Nielsen, 1994; D.C. Smith et al., 1982).

$>\quad$ "Shortcuts and accelerators": the system should offer shortcuts to expert users while simultaneously accepting less efficient but more intuitive forms of input from novice users (Nielsen, 1994; Molich \& Nielsen, 1990; Nielsen \& Molich, 1990).

$>\quad$ "Speak the user's language": the system should use only words and concepts that are already familiar to a novice user, without employing technical jargon (Nielsen, 1994; Molich \& Nielsen, 1990; Nielsen \& Molich, 1990).

\subsection{Heuristic evaluation of the usability of a generic "magical" environment}

By correlating these 11 selected usability heuristics with the typical elements of an environment that employs "magical" forms of HCI, it was possible to identify ways in which a generic magical environment may, by definition, be expected to eliminate or create usability problems for its operators. This analysis is presented in Figure 2. Some "magical" aspects of a magical environment (indicated in red) might be expected to primarily and significantly damage usability by violating multiple important usability heuristics; others (in green) might be expected to primarily and significantly enhance usability; yet others (not shaded in red or green) might be expected to have little impact or a mixed impact, enhancing usability in some ways while simultaneously impairing it in others. 
Ways in which the magicality of a generic magical environment will tend to eliminate or create usability problems for its human users

Type of magical practice involved in interaction with the environment

\section{Usability heuristics that are} exemplified by such magical practice

(i.e., ways in which magical practice enhances usability of the environment)
Usability heuristics that are violated by such magical practice

(i.e., ways in which magical practice impairs usability of the environment)

Means/ends

\section{Reliance on invisible}

copy-original links

Harnessing of invisible
agents or forces

Manipulation of complex, non-intuitive dynamics of "occult" causality
- Seeing/pointing vs. remembering/typing

- Familiar user's conceptual model

- Consistency: same thing looks the same

- Seeing/pointing vs. remembering/typing

- Salient repertoire of available actions

- Easy to discriminate action alternatives

- Aesthetic integrity, keep design simple

- Seeing/pointing vs. remembering/typing

- Seeing/pointing vs. remembering/typing

- Salient repertoire of available actions

- Easy to discriminate action alternatives
- Familiar user's conceptual model

Environment

Use of specially prepared

ritual implements

- Modeless interaction

Use of specially prepared

ritual clothing

- Modeless interaction

Reliance on powers that function

- Modeless interaction

only within ritual contexts

- Seeing/pointing vs. remembering/typing

Learning/cognition/articulation

Arcane and asocial

symbolic languages

- Speak the user's language

- Seeing/pointing vs. remembering/typing

- Aesthetic integrity, keep design simple

- Real-world conventions

- Familiar user's conceptual model

- Speak the user's language

Arcane and asocial gestures

- Salient repertoire of available actions

- Real-world conventions

- Familiar user's conceptual model

- Speak the user's language

- Seeing/pointing vs. remembering/typing

- Salient repertoire of available actions

Use of lengthy, complex

incantations

- Aesthetic integrity, keep design simple

- Feedback timely and accurate

- Shortcuts and accelerators

- Real-world conventions

Use of magic words

+ Shortcuts and accelerators

- Real-world conventions

+ Easy to discriminate action alternatives

- Seeing/pointing vs. remembering/typing

+ Speak the user's language

Emotion-driven

+ Shortcuts and accelerators

techniques for interaction
tetion-driven

+ Seeing/pointing vs. remembering/typing

+ Feedback timely and accurate

+ Familiar user's conceptual model

+ Salient repertoire of available actions

- Easy to discriminate action alternatives

Required mastery of an

esoteric body of knowledge

- Seeing/pointing vs. remembering/typing

- Familiar user's conceptual model

- Salient repertoire of available actions

- Real-world conventions

- Easy to discriminate action alternatives

Rules developed and

policed by an initiated elite

- Real-world conventions

- Seeing/pointing vs. remembering/typing

Development

Accessing of non-natural worlds

- Real-world conventions

- Modeless interaction

- Salient repertoire of available actions

- Easy to discriminate action alternatives

- Eamiliar user's conceptual model

Figure 2. Ways in which the magicality of a generic magical environment may be expected to eliminate or create usability problems for its users, insofar as it embodies or violates the most important usability heuristics for HCI identified by Nielsen; only one element (in green) exemplifies five or more heuristics, while five magical elements (in red) violate five or more heuristics. (Source: author's own design.) 
For example, interaction with a magical environment that requires users to learn and employ "Arcane and asocial symbolic languages" in order to manipulate it thereby reduces usability by violating several usability heuristics. To begin with, the environmental system fails to "Speak the user's language," insofar as it forces users to learn a new language. It violates the heuristic of "Seeing/pointing vs. remembering/typing," insofar as users must memorize the meaning of large quantities of arbitrary symbols of non-obvious significance, rather than being able to recognize and select desired actions from a menu of choices whose meaning is clear without previous study. It similarly violates the heuristic of "Aesthetic integrity, keep design simple," which bars the use of arbitrary images or symbols whose meaning is not obvious to a user. The fact that the language to be learned is arcane and asocial means that, by definition, it is not the sort of natural human language that is useful for conventional linguistic purposes, and the linguistic "Real-world conventions" familiar to users will not apply to it. Finally, the fact that the language is artificial, esoteric, and not grounded in references to ordinary everyday objects means that a user cannot rely on the "Familiar user's conceptual model" when attempting to remember or interpret the language's structure or contents.

On the other hand, by its nature, the element of magical practice that involves "Emotion-driven techniques for interaction" tends to facilitate the implementation of the most important HCI usability heuristics identified by Nielsen. A "magical" environment that is able to directly detect, interpret, and respond to users' moods, emotions, and desires in real time offers its users the opportunity to manipulate that environment in ways that are spontaneous, instantaneous, and natural and that do not require specialized training or the use of elaborate scripts. For example, a cyber-physical smart workplace that instantly and automatically pauses or "undoes" some action that was underway because it recognized that a user was unhappy with the action (as manifested in the user's unconscious facial expressions) thereby "Speaks the user's language" in an especially direct and intimate way and offers novel forms of "Shortcuts and accelerators" that do not even require a user to type on a keyboard, manipulate a mouse, or speak some instruction aloud.

Meanwhile, an environment that allows interaction through the "Use of magic words" - by which a user can trigger some desired effect by uttering a single predetermined word that has been arbitrarily selected by the system - thereby creates a mix of usability advantages and disadvantages. On the one hand, for example, it exemplifies the heuristic of employing "Shortcuts and accelerators"; on the other hand, it violates the principle of continuously displaying the "Salient repertoire of available actions" by forcing a user to accurately retain knowledge of all available magic words and their effects and to instantly recall the appropriate magic word, when desired.

For the 14 elements of magical practice, the number of usability heuristics that can be expected to be exemplified by a particular element ranges from 0 to 6 and the number of usability heuristics that can be expected to be violated ranges from 1 to 7 . Five of the magical elements ("Manipulation of complex, non-intuitive dynamics of 'occult' causality," "Arcane and asocial symbolic languages," "Use of lengthy, complex incantations," "Required mastery of an esoteric body of knowledge," and "Accessing of non-natural worlds") are conceptually linked with the violation of five or more HCI usability heuristics; in Figure 2, those magical elements are highlighted in red. Only one magical element ("Emotion-driven techniques for interaction") is associated with the exemplification of five or more usability heuristics; that element is highlighted in green.

\subsection{Heuristic evaluation of the usability of two constituent technologies of "magical" cyber-physical smart} workplaces

The cyber-physical smart workplace is a key feature of the emerging "cyber-physical organization" (Gladden, 2017), which typically comprises an array of "cyber-physical systems" (Gill, 2008; Wang, Vuran, \& Goddard, 2008), including "cyber-physical-social systems" that incorporate human beings and social robots (Liu, Yang, Wen, Zhang, \& Mao, 2011; Smirnov, Kashevnik, \& Ponomarev, 2015). As depicted in Figure 3, the cyber-physical organization and its cyber-physical smart workplace are characterized by the roboticization of organizational agency and action (Samani, Valino Koh, Saadatian, \& Polydorou, 2012; Ford, 2015; Sachs, 
Benzell, \& LaGarda, 2015; Gladden, 2017), deepened human-computer integration within the organizational workforce (Clark, 2004; McGee, 2008; Koops \& Leenes, 2012; Gladden, 2017), and the ubiquitization and non-localization of computational processes (Greenfield, 2006; Gladden, 2016, 2017; Coeckelbergh, 2011). A robustly cyber-physical organization constitutes a type of entity within which processes of posthumanization (Gladden, 2018c; Herbrechter, 2013) have exercised significant transformative influence; more specifically, its cyber-physical smart workplace can be understood as "technologically posthumanized," insofar as its incorporation of particular advanced technologies has expanded the workplace to includes members other than "natural" biological human beings who contribute to its structure, activity, and meaning by serving within it as decision-makers and intelligent social actors (Gladden, 2018c).

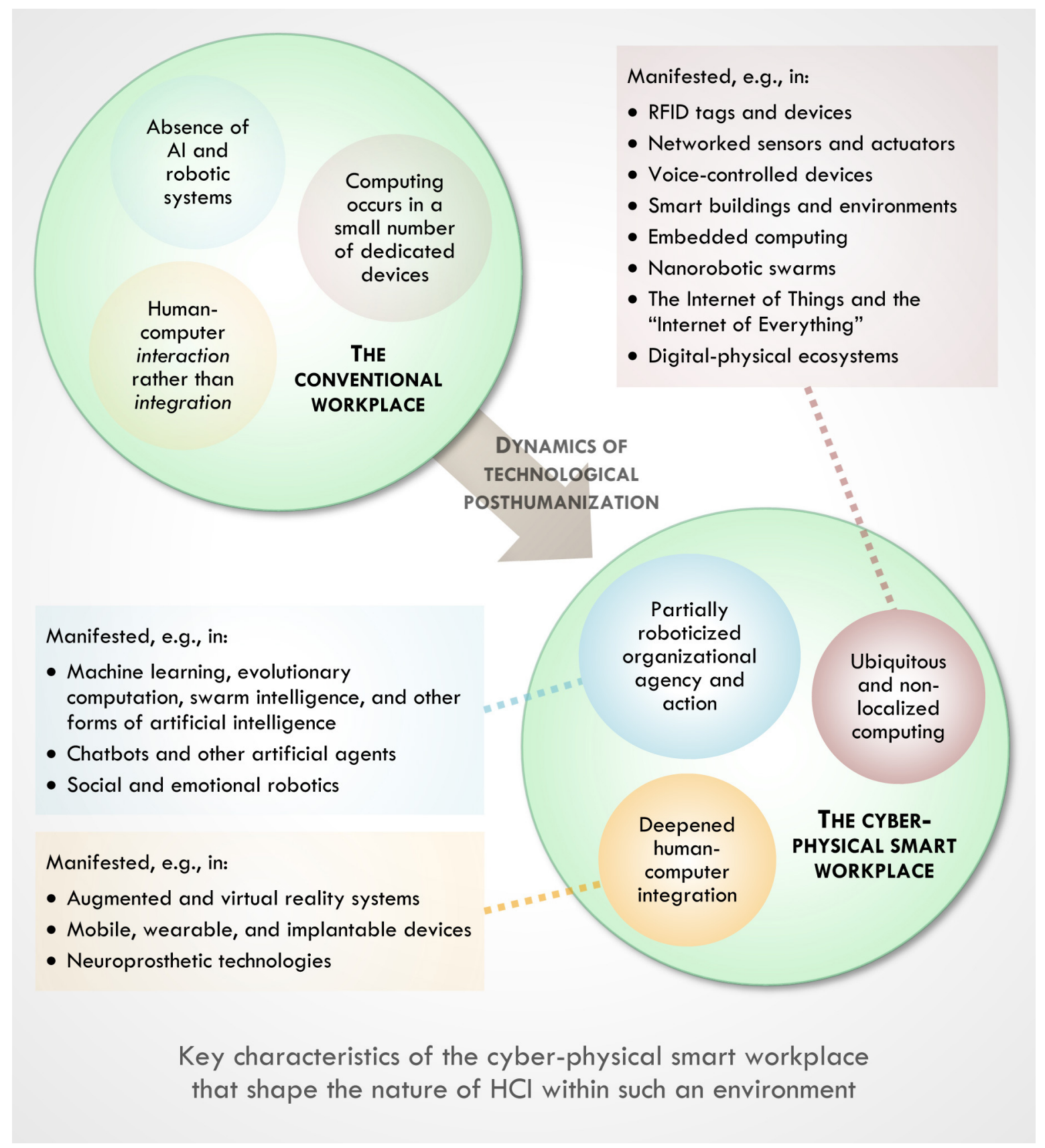

Figure 3. Key characteristics of the cyber-physical smart workplace, which incorporates a characteristic range of technologies and enables new forms of HCI. (Source: author's own design.) 
Analysis of Figure 2 suggests that - far from automatically offering a positively enhanced user experience any such cyber-physical smart workplace that incorporates forms of HCI that can properly be described as "magical" (from an anthropological perspective) may be at least as likely to lessen its usability and create a poorer user experience. To explore how that dynamic manifests itself in practice, this study considered in more detail the "magicality" of two particular types of technologies associated with the emerging cyber-physical smart workplace: those relating to (a) ambiently intelligent and IoT-enabled systems and (b) AR and VR systems.

The magicality of ambiently intelligent and IoT-enabled smart environments - By analyzing, comparing, and synthesizing texts that investigate the use of ambient intelligence, ubiquitous computing, cyber-physical systems, and IoT-enabled systems to create interactive smart workplace environments (Remagnino, Hagras, Monekosso, \& Velastin, 2005; Bohn, Coroamă, Langheinrich, Mattern, \& Rohs, 2005; Cook, Augusto, \& Jakkula, 2009; De Saulles, 2017; Kranz, 2017; Raj \& Raman, 2017; Liu et al., 2011; Gill, 2008; Wang et al., 2008; Poslad, 2011), it was possible to identify ways in which a cyber-physical smart workplace incorporating such technologies would offer its users a "magical" form of HCI. Figure 4 identifies particular aspects of ambiently intelligent and IoT-enabled systems that can be understood as creating a type of "magical" HCI; associates them with the relevant anthropological aspect of magical practice and sphere of HCI; and (through the shading of cells) indicates whether particular aspects of such ambiently intelligent and IoT-enabled systems are associated with magical practices that may generally be expected to have a beneficial, detrimental, or neutral or mixed impact on usability and user experience.

For example, such environments offer a new means of harnessing invisible, intelligent non-human entities or forces to produce some desired physical effect. According to the medieval Christian account of magic (developed by thinkers like St. Thomas Aquinas (1948)), many forms of magic implicitly or explicitly involved efforts to control disembodied demons that could manipulate physical objects. In a sense, within a contemporary workplace environment "enlivened" by cyber-physical systems, ambient intelligence, and the Internet of Things, embedded AI linked to ubiquitous sensors and actuators takes the place of demons: the human user of such a space might relocate heavy objects, adjust the lighting and temperature, open or close windows or doors, play particular audiovisual media, establish live audiovisual communication links with distant individuals, schedule future events, request particular pieces of information, or activate or deactivate devices simply by uttering a particular phrase or performing a certain type of gesture.

The magicality of augmented and virtual reality systems - Similarly, by analyzing literature that explores the emerging use of AR and VR systems in workplace settings (Kadavasal, Dhara, Wu, \& Krishnaswamy, 2007; Craig, 2013; Jerald, 2016; Aukstakalnis, 2017; Ewalt, 2018; Farshid, Paschen, Eriksson, \& Kietzmann, 2018), it was possible to offer a similar account of the impact of such technologies" "magicality" on HCI within the context of a cyber-physical smart workplace. That analysis is also presented in Figure 4.

For example, many types of VR systems incorporate new types of "ritual clothing" in the form of haptic feedback gloves and VR goggles that are not employed in traditional HCI and which allow their users to access a sort of "parallel world" whose contents are imperceptible to gathered bystanders who are not using such VR gear.

Moreover, VR systems that employ motion-detection technologies may require their users to master a collection of "arcane gestures" that produce no effects in the external physical world (other than amusing or perplexing any nearby observers) or when users are standing outside of the VR system's sensory boundaries but which may generate spectacular effects within the virtual world experienced by the users when they are performing such gestures within the "ritual context" of an activated VR system's zone of motion detection.

Such virtual worlds may also display "laws of nature" and forms of causality (Novak, 1991) that differ radically from those of the everyday physical world (Ingarden, 1974, 1970): for example, within a virtual world, a user may be able to levitate above the ground, move instantaneously across great distances, or "reverse time" and replay some recent sensory experience. Users who gradually come to master the intricacies of such $\mathrm{HCI}$ are, 
Gladden, M. E.

in effect, becoming initiated into a particular type of (digital-physical) magical practice.

\subsection{Divergent ways in which the magicality of classical computing and the cyber-physical smart workplace} impact HCI UX

For comparative purposes, Figure 4 also builds on Freedman (1973) to offer an analysis of the magicality of "classical" forms of HCI grounded in conventional computer programming and software use of the sort that became common beginning in the 1970s. For example, a block of source code written in a programming language like $\mathrm{C}++$ displays a high "coefficient of weirdness": while it possesses a unique grammar and syntax, such code is incomprehensible to non-programmers, and it is not the sort of language that can be used for everyday conversations in the home or workplace. Moreover, snippets of code written in such a language produce no notable effects when simply pasted into a document in a word processor; only when the same lines of code are inserted into a file within the "ritual context" of a programmer's integrated development environment (IDE) or source code editor can they produce dramatic and unexpected effects - for example, by causing a bird to soar above a forest on the computer screen or elaborate fractals to appear when the compiled executable program is run. Similarly, conventional programmers may learn obscure keyboard shortcuts or prepare macros that allow them to perform some arcane "gesture" upon the keyboard that will generate what to the uninitiated appear to be startling and inexplicable effects.

A comparison of the columns presented in Figure 4 makes it possible to formulate the following observations:

$>$ The incorporation of ambiently intelligent and IoT-enabled systems and AR/VR systems creates the potential for the cyber-physical smart workplace to eliminate some "magical" aspects of classical computer programming and software use (i.e., their reliance on "Arcane and asocial symbolic languages" and the "Use of lengthy, complex incantations") that are conceptually linked with numerous usability heuristic violations. In this way, the new forms of intuitive, physical, social HCI made possible by the cyber-physical smart workplace open the door to offering improved user experiences.

$>\quad$ The cyber-physical smart workplace's use of ambiently intelligent and IoT-enabled systems and AR/VR systems also has the potential to enhance usability and UX by incorporating a new element of magical practice ("Emotion-driven techniques for interaction") that is absent in classical computer programming and software use but which is conceptually linked with the successful exemplification of a significant number of important usability heuristics.

$>\quad$ At the same time, though, the cyber-physical smart workplace's use of ambiently intelligent and IoT-enabled systems and AR/VR systems promises to preserve some of the "magical" elements of classical computing that are conceptually linked with significant usability heuristic violations (i.e., "Manipulation of complex, non-intuitive dynamics of 'occult' causality," "Required mastery of an esoteric body of knowledge," and "Accessing of non-natural worlds"). However, the specific form that these magical elements take within the cyber-physical smart workplace differs from those found in classical computing.

\section{Discussion}

Reflection on the study's findings makes it possible to discern a number of managerial implications for scholars and industry. These are discussed below, along with limitations of the study and potential directions for future research. 
Comparison of the usability/UX impacts of the "magicality" of classical computing and two technologies of the cyber-physical smart workplace

\begin{tabular}{c|c|c}
$\begin{array}{c}\text { Magical practices employed } \\
\text { with classical } \\
\text { computer programming } \\
\text { and software use }\end{array}$ & $\begin{array}{c}\text { Magical practices employed with two constituent technologie } \\
\text { of the emerging cyber-physical smart workplace }\end{array}$ \\
$\begin{array}{c}\text { Ambiently intelligent } \\
\text { and loT-enabled systems }\end{array}$ & $A R$ and VR systems
\end{tabular}

\begin{tabular}{|c|c|c|c|}
\hline \multicolumn{4}{|l|}{ Means/ends } \\
\hline $\begin{array}{l}\text { Reliance on } \\
\text { invisible copy- } \\
\text { original links }\end{array}$ & $\begin{array}{l}\text { - Program use is based on the } \\
\text { relationship between groups of } \\
\text { electronically stored bits and } \\
\text { visible "objects" represented on } \\
\text { screen by groups of pixels }\end{array}$ & $\begin{array}{l}\text { - Embedded computers maintain and } \\
\text { utilize some internal representation } \\
\text { of the external physical environment }\end{array}$ & $\begin{array}{l}\text { - A user's avatar in VR is manipu- } \\
\text { lated through movements of the } \\
\text { user's real physical body }\end{array}$ \\
\hline $\begin{array}{l}\text { Harnessing of } \\
\text { invisible agents } \\
\text { or forces }\end{array}$ & $\begin{array}{l}\text { - Compiler } \\
\text { - Finished executable program }\end{array}$ & $\begin{array}{l}\text { - Wirelessly networked embedded } \\
\text { computers can invisibly communicate } \\
\text { with and control one another }\end{array}$ & $\begin{array}{l}\text { - Processes that transform user } \\
\text { movements into real-time effects } \\
\text { within AR/VR occur invisibly within } \\
\text { the system's computer }\end{array}$ \\
\hline $\begin{array}{l}\text { Manipulation of } \\
\text { complex, non- } \\
\text { intuitive dynamics of } \\
\text { "occult" causality }\end{array}$ & $\begin{array}{l}\text { - Computer uses unseen processes to } \\
\text { transform mouse or keyboard input } \\
\text { into altered patterns of pixels on a } \\
\text { monitor }\end{array}$ & $\begin{array}{l}\text { Objects embedded with networked } \\
\text { robotic actuators can move, } \\
\text { transform, and react in ways } \\
\text { impossible for normal objects }\end{array}$ & $\begin{array}{l}\text { Real-world bodily movements } \\
\text { may generate non-intuitive, } \\
\text { non-isomorphic effects in VR }\end{array}$ \\
\hline
\end{tabular}

\begin{tabular}{|llll}
\hline Environment & Keyboard & - Mouse & - Monitor \\
- Floppy disks & $\begin{array}{l}\text { Smart speakers and other networked } \\
\text { and Al-enabled devices serve as } \\
\text { portals to access and control the } \\
\text { loT-enabled environment }\end{array}$ & $\begin{array}{l}\text { Use of handheld controllers to } \\
\text { manipulate one's avatar and the } \\
\text { VR environment }\end{array}$ \\
$\begin{array}{l}\text { Use of specially } \\
\text { prepared ritual } \\
\text { implements }\end{array}$ & $\begin{array}{l}\text { Smart surfaces or other devices } \\
\text { as tools for engaging with AR }\end{array}$ \\
$\begin{array}{l}\text { Use of specially } \\
\text { prepared ritual } \\
\text { clothing }\end{array}$ & $\begin{array}{l}\text { Clothing with embedded RFID tags } \\
\text { facilitates access to or interaction with } \\
\text { the loT-enabled environment }\end{array}$ & $\begin{array}{l}\text { Use of VR goggles, earphones, } \\
\text { and haptic feedback gloves to } \\
\text { enter a virtual environment }\end{array}$ \\
\hline $\begin{array}{l}\text { Reliance on powers } \\
\text { that function only } \\
\text { within ritual } \\
\text { contexts }\end{array}$ & $\begin{array}{l}\text { - Source code editor or IDE within } \\
\text { which a programming language } \\
\text { generates effects }\end{array}$ & $\begin{array}{l}\text { A user's speech and gestures trigger } \\
\text { desired digital-physical effects only } \\
\text { within an active smart environment that } \\
\text { recognizes the individual as an } \\
\text { authorized user }\end{array}$ & $\begin{array}{l}\text { Specialized gestures only } \\
\text { produce effects when using } \\
\text { VR gear }\end{array}$ \\
\hline
\end{tabular}

\begin{tabular}{|c|c|c|c|}
\hline \multicolumn{4}{|c|}{ Learning/cognition/articulation } \\
\hline $\begin{array}{l}\text { Arcane and } \\
\text { asocial symbolic } \\
\text { languages }\end{array}$ & $\begin{array}{l}\text { - Conventional programming } \\
\text { languages } \\
\text { - Variables, operators, and functions }\end{array}$ & & \\
\hline $\begin{array}{l}\text { Arcane and } \\
\text { asocial gestures }\end{array}$ & $\begin{array}{l}\text { - Left-click, right-click, and } \\
\text { other mouse actions } \\
\text { - Keyboard shortcuts like Ctrl+C } \\
\text { or Ctrl+Alt+Del }\end{array}$ & $\begin{array}{l}\text { - Specialized gestures can trigger } \\
\text { responses by smart-building systems } \\
\text { when recognized and interpreted by } \\
\text { the systems' motion-detection sensors } \\
\text { and Al }\end{array}$ & $\begin{array}{l}\text { - Specialized gestures trigger ef- } \\
\text { fects in AR/VR when recognized } \\
\text { and interpreted by the system's } \\
\text { motion-detection sensors and Al }\end{array}$ \\
\hline $\begin{array}{l}\text { Use of lengthy, } \\
\text { complex incantations }\end{array}$ & $\begin{array}{l}\text { - Recording of in-program macros } \\
\text { - Code snippets }\end{array}$ & & \\
\hline $\begin{array}{l}\text { Use of magic } \\
\text { words }\end{array}$ & - Command-prompt instructions & $\begin{array}{l}\text { Specialized words or phrases awaken } \\
\text { and manipulate voice-controlled } \\
\text { systems }\end{array}$ & $\begin{array}{l}\text { - Specialized words or phrases } \\
\text { awaken and manipulate voice- } \\
\text { controlled systems }\end{array}$ \\
\hline $\begin{array}{l}\text { Emotion-driven } \\
\text { techniques for } \\
\text { interaction }\end{array}$ & & $\begin{array}{l}\text { - Through incorporation of emotional } \\
\text { robotics and ubiquitous computing, the } \\
\text { whole environment can interpret and } \\
\text { respond to a user's emotions, moods, } \\
\text { and paralinguistic expression }\end{array}$ & $\begin{array}{l}\text { - Motion detection can allow } \\
\text { "vigorous" input (e.g., in the } \\
\text { form of waving, punching, } \\
\text { kicking, or jumping), rather than } \\
\text { just keystrokes on a keyboard }\end{array}$ \\
\hline $\begin{array}{l}\text { Required mastery } \\
\text { of an esoteric body }\end{array}$ & $\begin{array}{l}\text { - The need to learn hardware } \\
\text { architecture and capabilities }\end{array}$ & $\begin{array}{l}\text { - The need to learn "secret," } \\
\text { non-intuitive phrases and gestures }\end{array}$ & $\begin{array}{l}\text { - Learning the idiosyncrasies of } \\
\text { particular } A R / V R \text { systems and } \\
\text { programs }\end{array}$ \\
\hline of knowledge & $\begin{array}{l}\text { - The need to learn principles of } \\
\text { software design and operation }\end{array}$ & that trigger environmental responses & $\begin{array}{l}\text { - Learning to successfully manipu- } \\
\text { late non-intuitive } 3 \mathrm{D} \text { controls }\end{array}$ \\
\hline $\begin{array}{l}\text { Rules developed } \\
\text { and policed by an } \\
\text { initiated elite }\end{array}$ & $\begin{array}{l}\text { - Programming languages } \\
\text { and conventions }\end{array}$ & $\begin{array}{l}\text { - SDKs for commercial smart-building } \\
\text { devices and systems }\end{array}$ & $\begin{array}{l}\text { - SDKs for commercial AR/VR } \\
\text { devices and systems }\end{array}$ \\
\hline \multicolumn{4}{|l|}{ Development } \\
\hline $\begin{array}{l}\text { Accessing of } \\
\text { non-natural worlds }\end{array}$ & $\begin{array}{l}\text { - The fictional "worlds" displayed on } \\
\text { a computer monitor by software } \\
\text { programs need not follow normal } \\
\text { laws of nature }\end{array}$ & $\begin{array}{l}\text { - Through embedded sensors, actuators, } \\
\text { and Al, the whole physical environment } \\
\text { becomes "magically responsive" }\end{array}$ & $\begin{array}{l}\text { - A user is functionally trans- } \\
\text { ported to an interactive virtual } \\
\text { world that need not adhere to } \\
\text { the normal laws of nature }\end{array}$ \\
\hline
\end{tabular}

Figure 4. The "magicality" of the cyber-physical smart workplace has the potential to eliminate some of the violations of HCI usability heuristics (indicated in red) found in classical computing and add new violations of its own (also in red), while at the same time beneficially exemplifying other usability heuristics (in green) that are not embodied by classical computing and HCI. (Source: author's own design.) 


\subsection{Managerial implications for scholars}

By demonstrating how new, technologically posthumanizing workplace technologies can be analyzed using conceptual frameworks that have been previously applied to study historical forms of "magical practice," the study makes it easier for anthropologists and other social scientists to investigate the emerging cyber-physical smart workplace as a venue in which human beings interact with other human agents, nonhuman agents and tools, and their broader environment in qualitatively novel ways. Conversely, for scholars in the field of management who are striving (a) to understand how human workers instinctively interact with new cyber-physical smart workplaces or (b) to identify best practices for how human workers can most effectively interact with such cyber-physical smart workplaces, this study's findings provide a blueprint for adapting established methodologies from social and philosophical anthropology and applying them in a new context. The study thus provides a transdisciplinary "bridge" that allows insights from the field of anthropology to inform ongoing research in the fields of technology management and HCI - and vice versa. This makes it possible for scholars to draw creatively on findings from other disciplines in a way that respects each field's autonomy while avoiding needless reduplication of effort. Moreover, for philosophers of technology, the study provides an in-depth analysis of a particular type of technological posthumanization and its impacts that can serve as raw material for further reflection.

\subsection{Managerial implications for industries that design and produce "magical” workplace technologies}

For companies that design and produce technologies that contribute to cyber-physical smart workplace environments (including voice-activated smart assistants, building automation systems, industrial AR/VR systems, interactive holographic surfaces, and ambiently intelligent spaces), the study provides a meaningful new conceptual framework for UX analysis and the planning of human-computer interaction. It reminds us that "magical" workplace technologies tap into longstanding and deeply rooted patterns of cognition and social behavior according to which human beings frequently come to view complex, unpredictable, and uncontrollable surroundings as "magical" (to a greater or lesser degree) and seek to understand and manipulate those environments through magical practices that are emotionally appealing but of little or no practical effectiveness. Such dynamics create both opportunities and dangers for the producers of cyber-physical smart workplace technologies: the study identifies one element of magical practice (i.e., "Emotion-driven techniques for interaction") that designers of cyber-physical smart workplaces can incorporate into HCI within their environments that will likely enhance usability and improve UX, along with five other elements of magical practice (discussed in Section 3.4) that should generally be avoided when designing HCI for cyber-physical smart workplaces, insofar as they are likely to damage usability and UX.

Moreover, the study's findings suggest that (a) various cyber-physical smart workplace technologies (e.g., ambiently intelligent and IoT-enabled systems and AR/VR systems) may possess similar dynamics of beneficial and detrimental magicality, while (b) the dynamics of beneficial and detrimental magicality found collectively in cyber-physical smart workplace technologies differ significantly from those found in older forms of conventional computer programming and HCI. This indicates that (a) despite the superficial differences of their technologies, producers of diverse cyber-physical smart workplace systems may be able to draw meaningful insights from one another regarding best practices for HCI, and (b) any producers of workplace technologies that are still relying on analyses of the "magicality" of technology grounded in studies of conventional computer programming and HCI should reevaluate the appropriateness of their dependence on such (increasingly outdated) research.

\subsection{Managerial implications for industries that utilize "magical” workplace technologies}

For organizations that utilize cyber-physical smart workplaces, the magicality of such environments has implications for the hiring and training of workers, the ease with which such environments can be utilized and repaired, and the scope of the organizations' strategic competition. 
New emphases for hiring and training: From engineering to the arts - If - thanks to its sophisticated embedded AI - a cyber-physical smart workplace becomes directly sensitive and immediately responsive to the wishes and behaviors of everyday occupants in the manner described above, then there is no longer such a great need for an organization to employ expert programmers and specialized technicians to operate that environment: even an ordinary user can elicit desired responses from an AI-enabled smart environment without needing to have mastered obscure programming languages or software design principles. One might interpret such a development as a reduction in the magicality of the environment, whose functioning becomes "democratized" and less dependent on a small, initiated elite of computer programmers who possess the esoteric knowledge needed to control it. Alternatively, one might argue that within such a smart environment, even ordinary users will gain extraordinary and unusual new powers for manipulation and control - thereby enhancing the seeming "enchantment" of the workplace.

In either case, there will always be an important role for those workers who better understand the environment's governing AI - who know the tricks for "taming," "coaxing," or otherwise manipulating it and who understand how to more ingeniously exploit its potential, even if they do so by employing a certain tone of voice or finesse in their physical gestures, rather than by dictating the environment's behavior through the use of a programming language. Investigation of such possibilities can draw beneficially on the research of computer scientist and philosopher Alan N. Shapiro (2014), whose work explores ways in which future forms of HCI may enable computer programs to be brought into existence (or computerized devices to be manipulated) as a "self-expressive act of creativity" that is more akin to the creation of art or poetry than a purely logical, mathematical exercise.

From the perspective of HCI, the most relevant distinction in such a situation may no longer be between "ordinary users" and "expert programmers" but between the "ordinary occupants" of a cyber-physical smart workplace and those "adepts" who are skilled at manipulating it through new magical forms of speech, gesture, and other social behaviors. Indeed, a concept explored in numerous works of fiction is that of near-future "cyberadepts" (Hume, 1995), "virtual adepts" (Bridges, Brucato, Campbell, Gaudreau, McCoy, et al., 1998), "technomancers" (Bridges et al., 1998), or "technoshamans" (Hume, 1995) who are so attuned to the nature of the surrounding environment as a computerized system that they can essentially "reprogram" the world around them through a sheer act of will. To date, the limited real-world manifestations of self-conscious "technoshamanism" (e.g., by figures like Michael Allison (2015)) are primarily either artistic experiment, parody, provocation, or wishful thinking rather than serious, sincere "magical practice" - because the types of technology that could support such practice are only now beginning to emerge. However, the development of cyber-physical organizations and their technologically posthumanized workplaces are a further step toward facilitating such new forms of HCI. If the successful manipulation of cyber-physical smart workplaces is indeed based not primarily on computer programming skills but on physical and emotional talents of the sort commonly employed in dance, theatrical performance, rhetoric, and coaching, then organizations utilizing cyber-physical smart environments may need to reprioritize the skills that they seek to identify or inculcate when recruiting or training employees; for a growing number of jobs located in such workplaces, training in the arts and humanities may become more desirable than a knowledge of science, mathematics, and engineering.

Easier to use, harder to repair: The cyber-physical smart workplace as a "black box" for workers - It is arguably not the obvious superficial aspects - like the use of VR goggles and haptic feedback gloves - that most differentiate the "new" types of magical practice introduced into the cyber-physical smart workplace from the "old" types of magical practice mastered by traditional computer programmers. Rather, it is the new experience of environmental agency enjoyed by the designers, operators, and ordinary users of such workplaces that may represent the greatest qualitative change to HCI. This change results from two interrelated ways in which real-time semi-autonomous analysis and decision-making by sophisticated forms of AI (and not human programmers or sysadmins) shape how such an environment responds to human input. On the one hand, AI becomes the new mediator that determines exactly when and how input provided by human workers (e.g., through their speech or gestures) will be transformed into particular types of sensory stimuli or behaviors by 
physical objects; at the same time, though, such AI conceals from the human workers the precise mechanisms by which it works and hides its involvement in the process.

For example, in earlier workplaces, causing a robotic arm to rotate in a certain way might have required a programmer to spend hours writing detailed source code or an expert user to meticulously train the robot using a specialized "teach pendant"; such employees were intimately aware (and continuously reminded) of all the individual technological mechanisms and detailed procedural steps that were involved with controlling the robot's actions. However, within emerging types of cyber-physical smart workplaces of the sort discussed here, an ordinary employee might - without any elaborate training - be able to walk into a smart environment, say aloud to a robotic system, "Do as I do," and then watch as the robot's manipulator arm imitates the real-time motions of the employee's own arm.

Such a workplace becomes a sort of "black box" (Hynes, 2018) in which employees need not understand the precise technological mechanisms that underlie its behavior; they need only learn what types of input will generate which types of real-time responses within the physical or virtual environment. Human workers who become immersed in such an environment's cybernetic feedback loops might over time even "forget" the fact that a computerized AI system is orchestrating the environment's behavior, behind the scenes; it might instead appear as though the whole environment itself is a kind of quasi-organism or ecosystem that is directly sensitive and "magically responsive" to the worker's actions. As long as all of its constituent technologies continue to function flawlessly, such an environment may be easier for workers (even new and untrained ones) to manipulate than previous IT-heavy environments; however, when unexpected problems eventually occur with the environment (e.g., due to random hardware failures), they might be more difficult for ordinary workers to resolve, as the workers will possess very limited understanding of the environment's underlying technologies. In effect, such cyber-physical smart workplaces may become easier for an organization's personnel to use but harder for them to repair; this makes it more important for organizations to design such systems to display high reliability and a long mean time between failures (MTBF).

The cyber-physical smart workplace: A new "magical" strategic battleground for organizations Historically, organizational workplaces have been limited in size: a given company's employees might be housed within a single factory or office building or within a collection of numerous such buildings found in particular geographical locations. However, the creation of VR-enabled online virtual worlds allows employees, (potential) customers, and other stakeholders who are scattered physically around the entire planet to "inhabit" and interact within a single shared virtual space. Similarly, by accessing the globalized Internet of Things, an organization can extend its workplace into public spaces or the homes of employees or (potential) customers by sensing what is happening and acting physically in those environments through a diverse array of networked devices.

This can, in effect, expand the "enchanted" cyber-physical smart workplace to potentially encompass much of the world's cyber-physical and digital-physical ecosystem, within which one organization's workplace would overlap with those of many other organizations. Such magical realms are not simply an "internal" workplace or another profit-generating service offered to consumers; they constitute a new (virtual) strategic sphere within which organizations can compete against one another for information, influence, power, financial resources, and customer loyalty.

Given the importance of magical elements of HCI of the sort described in this study to the creation, operation, and effective use of such digital-physical realms by organizational "technomancers," the question arises of whether the functioning of such environments can be fully and adequately documented, analyzed, and explained solely by using established concepts found in traditional management disciplines like marketing, logistics, finance, enterprise architecture, and HR management - or whether it can be more robustly described and meaningfully interpreted by incorporating taxonomies, typologies, and other concepts from the social anthropological or philosophical anthropological study of magical practice. Organizations that maintain such globalized cyber-physical smart workplaces may thus increasingly need to expand their workforces to 
incorporate new expertise from the social sciences.

\subsection{Limitations of this study}

A notable limitation of this study is the fact that it has only offered a prospective usability evaluation of the magical elements of two types of technologies found within the emerging cyber-physical smart workplace, which yielded similar profiles for the ways in which their magicality might be expected to enhance or impair usability and user experience. As indicated in Figure 3, though, such workplaces encompass diverse other technologies relating, for example, to machine learning, swarm intelligence, mobile and wearable devices, and neuroprostheses. It is possible that a prospective usability evaluation of the magical elements of such additional technologies might suggest that the impact of their magicality on usability and UX will differ significantly from those of the ambiently intelligent and IoT-enabled systems and AR/VR systems investigated here. Moreover, the ongoing emergence of new technologies and the rapid and accelerating pace of technological change within organizations means that any such analyses must be revisited regularly in order to take into account new workplace technologies and the novel forms of HCI that they facilitate.

\subsection{Directions for future research}

In addition to carrying out additional prospective usability evaluations for specific technologies of the sort just described, it will become increasingly feasible to carry out qualitative empirical studies of workers' lived experiences of magicality within cyber-physical smart workplaces and quantitative studies of the impacts of such workplaces' magicality on their efficiency and effectiveness, as such workplaces become more widely and robustly implemented within growing numbers of organizations.

\section{Conclusion}

This study has shown that HCI within emerging cyber-physical smart workplaces is not simply "magical" in a metaphorical sense; from an anthropological perspective, it can be understood as involving true magical practices. However, as demonstrated above, the "magicality" of such environments is not an entirely positive trait; rather, magicality is a complex phenomenon that has the potential to both improve and damage usability and user experience in diverse ways. Moreover, the usability and UX impacts of magicality in emerging technologies for the cyber-physical smart workplace have been shown to differ substantially from the effects of magicality in classical computing. This suggests that the magicality of computing technologies and its impacts on users have already evolved significantly in recent decades and may continue to evolve further in the future. It is thus difficult to offer a definitive study of the magicality of computing technologies in any one work. However, it is hoped that by employing approaches like the one formulated and applied in this text to aid in the understanding, design, and execution of HCI within cyber-physical smart workplaces, the "magical" aspects of such environments can be managed in ways that generate the best possible user experience for the employees, customers, and other stakeholders who may occupy or interact with them.

\section{References}

Adams, T., Olsen, K., \& Smith, M.A. (2013). Thinking about magic in medieval and early modern Europe. Parergon, 30(2), 1-10. https://doi.org/10.1353/pgn.2013.0086

Allison, M. (2015). Ecstatic computation: Virtual reality ritual and performance. Retrieved from http://michaelallison.lol/projects/ecstaticcomputation

Apple Computer. (1992). Macintosh human interface guidelines. Reading, MA: Addison-Wesley. Aquinas, T. (1948). Summa theologica 2.2.96. New York: Benzinger Bros.

Aukstakalnis, S. (2017). Practical augmented reality: A guide to the technologies, applications, and human factors for $A R$ and VR. New York: Pearson Education, Inc.

Bohn, J., Coroamă, V., Langheinrich, M., Mattern, F., \& Rohs, M. (2005). Social, economic, and ethical 
implications of ambient intelligence and ubiquitous computing. In W. Weber, J. M. Rabaey, \& E. Aarts (Eds.), Ambient intelligence (pp. 5-29). Berlin, Heidelberg: Springer. https://doi.org/10.1007/3-540-27139-2_2

Bridges, B., Brucato, P., Campbell, B., Gaudreau, R., McCoy, A.L., McLaughlin, J., \& Robey, J.R. (1998). Technomancer's toybox. Clarkston, GA: White Wolf Game Studio.

Brottman, M. (2009). Psychoanalysis and magic: Then and now. American Imago, 66(4), 471-489. https://doi.org/10.1353/aim.0.0067

Bubandt, N., \& Willerslev, R. (2015). The dark side of empathy: Mimesis, deception, and the magic of alterity. Comparative Studies in Society and History, 57(1), 5-34. https://doi.org/10.1017/S0010417514000589

Clark, A. (2004). Natural-born cyborgs: Minds, technologies, and the future of human intelligence. Oxford: Oxford University Press.

Clarke, A.C. (1973). Hazards of prophecy: The failure of imagination. In Profiles of the future (pp. 12-21). London: Pan.

Coeckelbergh, M. (2018). Scientific suspects, romantic witnesses? Magic technologies, alienation, and self-destruction in the Anthropocene. Glimpse, 19, 39-45. https://doi.org/10.5840/glimpse2018194

Coeckelbergh, M. (2011). From killer machines to doctrines and swarms, or why ethics of military robotics is not (necessarily) about robots. Philosophy \& Technology, 24(3), 269-78. https://doi.org/10.1007/s13347-011-0019-6

Collins, D. (2003). Nature, cause, and agency in Greek magic. Transactions of the American Philological Association, 133, 17-49. https://doi.org/10.1353/apa.2003.0003

Collins, S. (2004). Technology and magick. SCAN Journal of Media Arts Culture, 1(2).

Cook, D. J., Augusto, J. C., \& Jakkula, V. R. (2009). Ambient intelligence: Technologies, applications, and opportunities. Pervasive and Mobile Computing, 5(4), 277-298. https://doi.org/10.1016/j.pmcj.2009.04.001

Craig, A. B. (2013). Understanding augmented reality: Concepts and applications. Waltham, MA: Morgan Kaufmann. https://doi.org/10.1016/B978-0-240-82408-6.00002-3

Da Silva de Queiroz Pierre, R. (2015). Heuristics in design: A literature review. Procedia Manufacturing, 3, 6571-6578. https://doi.org/10.1016/j.promfg.2015.07.961

Dąbrowska, K. M. (2010). Secret language in oral and graphic form: Religious-magic discourse in Aztec speeches and manuscripts. Oral Tradition, 25(2). https://doi.org/10.1353/ort.2010.0026

Davila, J. R. (2002). Shamanic initiatory death and resurrection in the Hekhalot literature. In P. Mirecki \& M. Meyer (Eds.), Magic and ritual in the ancient world (pp. 283-302). Leiden: Brill. https://doi.org/10.1163/9789047400400_016

De Saulles, M. (2017). The internet of things and business. New York: Routledge.

Dieleman, J. (2011). Scribal practices in the production of magic handbooks in Egypt. In Continuity and innovation in the magical tradition (pp. 85-118). Leiden: Brill. https://doi.org/10.1163/ej.9789004203518.i-390.24

Do, E. Y. L. (2013). Designing interactive computing for happy healthy life. In Intelligent interactive technologies and multimedia (pp. 1-13). Berlin, Heidelberg: Springer. https://doi.org/10.1007/978-3-642-37463-0_1

Durkheim, É. (1995). Elementary forms of religious life. Fields, K. E., translator. New York: The Free Press.

Eleta, P. (1997). The conquest of magic over public space: Discovering the face of popular magic in contemporary society. Journal of Contemporary Religion, 12(1), 51-67. https://doi.org/10.1080/13537909708580789

Enzheng, T. (2002). Magicians, magic, and shamanism in ancient China. Journal of East Asian Archaeology, 4(1), 27-73. https://doi.org/10.1163/156852302322454495

Ewalt, D. (2018). Defying reality: The inside story of the virtual reality revolution. New York: Blue Rider Press.

Farshid, M., Paschen, J., Eriksson, T., \& Kietzmann, J. (2018). Go boldly! Explore augmented reality (AR), virtual reality (VR), and mixed reality (MR) for business. Business Horizons, 61(5), 657-663.

Ford, M. (2015). Rise of the robots: Technology and the threat of a jobless future. New York: Basic Books. 
Novel forms of "magical" human-computer interaction within the cyber-physical smart workplace

Fragoso, S., \& Reis, B. M. S. (2016). Ludic re-enchantment and the power of locative games: A case study of the game Ingress. In International conference on culture, technology, and communication (pp. 131-148). Cham: Springer. https://doi.org/10.1007/978-3-319-50109-3_9

Frazer, J. G. (2009). The golden bough: A study in magic and religion. Oxford: Oxford University Press. https://doi.org/10.1017/CBO9781139207676

Freedman, D. (1973). Computer Magic. In SIGCPR '73 Proceedings of the $11^{\text {th }}$ annual SIGCPS computer personnel research conference (pp. 1-9). New York: Association for Computing Machinery (ACM). https://doi.org/10.1145/800120.803914

Friedman, T. (2009). The politics of magic: Fantasy media, technology, and nature in the 21 st century. Scope: An Online Journal of Film and Television Studies, 14.

Gell, A. (1992). The technology of enchantment and the enchantment of technology. In Anthropology, art and aesthetics (pp. 40-63). Oxford: Oxford University Press.

Gill, H. (2008). From vision to reality: Cyber-physical systems. In HCSS national workshop on new research directions for high confidence transportation CPS: automotive, aviation, and rail.

Gladden, M. E. (2018a). Ingardenowska „fenomenologia systemowa” jako podstawa posthumanizowanej praktyki architektury / An Ingardenian "systems phenomenology" as the basis for posthumanized architectural practice. Teka Komisji Urbanistyki i Architektury, 46, 127-138.

Gladden, M. E. (2018b). A phenomenological analysis of the posthumanized future workplace. Kwartalnik Nauk o Przedsiębiorstwie, 48, 31-39. https://doi.org/10.5604/01.3001.0012.7776

Gladden, M. E. (2018c). Sapient circuits and digitalized flesh: The organization as locus of technological posthumanization (2nd ed.). Indianapolis: Defragmenter Media.

Gladden, M. E. (2017). Strategic management instruments for cyber-physical organizations: Technological posthumanization as a driver of strategic innovation. International Journal of Contemporary Management, 16(3), 139-155. https://doi.org/10.4467/24498939IJCM.17.026.7546

Gladden, M. E. (2016). The diffuse intelligent other: An ontology of nonlocalizable robots as moral and legal actors. In M. Nørskov (Ed.), Social robots: Boundaries, potential, challenges (pp. 177-198). Farnham: Ashgate. https://doi.org/10.4324/9781315563084-10

Greenfield, A. (2006). Everyware: The dawning age of ubiquitous computing. Berkeley, CA: New Riders.

Greenwood, S. (2009). The anthropology of magic. Oxford: Berg.

Hagen, A. L. (2017). Sketching with knives: Architects \& the confidence theory of magic. Anthropology Today, 33(2), 24-27. https://doi.org/10.1111/1467-8322.12338

Hanegraaff, W. J. (2003). How magic survived the disenchantment of the world. Religion, 33(4), 357-380. https://doi.org/10.1016/S0048-721X(03)00053-8

Herbrechter, S. (2013). Posthumanism: A critical analysis. London: Bloomsbury.

Holcomb, R., \& Tharp, A. L. (1991). What users say about software usability. International Journal of HumanComputer Interaction, 3(1), 49-78. https://doi.org/10.1080/10447319109525996

Howard, J. (2014). Game magic: A designer's guide to magic systems in theory and practice. Boca Raton: CRC Press. https://doi.org/10.1201/b16848

Hubert, H., \& Mauss, M. (1902). Esquisse d'une théorie générale de la magie. L’Année sociologique (1896/1897-1924/1925), 7, 1-146.

Hume, P. R. (1995). Virtual realities 2.0: A Shadowrun sourcebook. Chicago: FASA.

Hynes, M. (2018). Shining a brighter light into the digital 'blackbox': A call for stronger sociological (re)engagement with digital technology design, development and adoption debates. Irish Journal of Sociology, 26(1), 94-126. https://doi.org/10.1177/0791603517741605

Ingarden, R. (1974). Über die kausale Struktur der realen Welt: Der Streit um die Existenz der Welt III. Tübingen: Max Niemeyer Verlag. https://doi.org/10.1515/9783110916201

Ingarden, R. (1970). Über die Verantwortung: Ihre ontischen Fundamente. Stuttgart: Reclam.

Ingarden, R. (1960). Spór o istnienie świata (Vol. 1). Warszawa: Państwowe Wydawnictwo Naukowe.

Ingarden, R. (1961). Spór o istnienie świata (Vol. 2). Warszawa: Państwowe Wydawnictwo Naukowe.

Javornik, A., Rogers, Y., Moutinho, A. M., \& Freeman, R. (2016). Revealing the shopper experience of using a 
“magic mirror" augmented reality make-up application. In Conference on designing interactive systems (pp. 871-882). New York: ACM. https://doi.org/10.1145/2901790.2901881

Jerald, J. (2016). The VR book: Human-centered design for virtual reality. New York: ACM. https://doi.org/10.1145/2792790

Kadavasal, M. S., Dhara, K. K., Wu, X., \& Krishnaswamy, V. (2007). Mixed reality for enhancing business communications using virtual worlds. In Proceedings of the 2007 ACM symposium on virtual reality software and technology (pp. 233-234). New York: ACM. https://doi.org/10.1145/1315184.1315236

Kaptelinin, V., Nardi, B. A., \& Macaulay, C. (1999). The activity checklist: A tool for representing the 'space' of context. Interactions, 6(4), 27-39. https://doi.org/10.1145/306412.306431

Keinan, G. (1994). Effects of stress and tolerance of ambiguity on magical thinking. Journal of Personality and Social Psychology, 67(1), 48. https://doi.org/10.1037/0022-3514.67.1.48

Klaniczay, G. (2013). The power of words in miracles, visions, incantations and bewitchments. In J. Kapalo, É, Pócs, \& W. Ryan (Eds.), The power of words: Studies on charms and charming in Europe (pp. 281-304). Budapest: Central European University Press.

Koops, B.-J., \& Leenes, R. (2012). Cheating with implants: Implications of the hidden information advantage of bionic ears and eyes. In M. N. Gasson, E. Kosta, \& D. M. Bowman (Eds.), Human ICT implants: Technical, legal and ethical considerations (pp. 113-34). The Hague: T.M.C. Asser Press. https://doi.org/10.1007/978-90-6704-870-5_10

Kranz, M. (2017). Building the Internet of Things: Implement new business models, disrupt competitors, transform your industry. Hoboken, NJ: John Wiley \& Sons.

Liu, Z., Yang, D., Wen, D., Zhang, W., \& Mao, W. (2011). Cyber-physical-social systems for command and control. IEEE Intelligent Systems, 26(4), 92-96. https://doi.org/10.1109/MIS.2011.69

Malinowski, B. (2005). Magic, science and religion. Whitefish, MT: Kessinger Publishing.

Malinowski, B. (1966). Coral gardens and their magic (Vol. 2). London: Allen \& Unwin.

Manning, M. C. (2014). Magic, religion, and ritual in historical archaeology. Historical Archaeology, 48(3), 1-9. https://doi.org/10.1007/BF03376934

McCarthy, J., \& Wright, P. (2018). The enchantments of technology. In Funology 2 (pp. 359-373). Cham: Springer. https://doi.org/10.1007/978-3-319-68213-6_23

McGee, E. M. (2008). Bioelectronics and implanted devices. In B. Gordijn \& R. Chadwick (Eds.), Medical enhancement and posthumanity (pp. 207-24). Netherlands: Springer. https://doi.org/10.1007/978-1-4020-8852-0_13

Mirelman, S. (2018). Mesopotamian magic in text and performance. In Mesopotamian medicine and magic (pp. 343-378). Leiden: Brill. https://doi.org/10.1163/9789004368088_018

Mohan, U. (2017). Clothing as a technology of enchantment: Gaze and glaze in Hindu garments. Magic, Ritual, and Witchcraft, 12(2), 225-244. https://doi.org/10.1353/mrw.2017.0022

Molich, R., \& Nielsen, J. (1990). Improving a human-computer dialogue. Communications of the ACM, 33(3), 338-348. https://doi.org/10.1145/77481.77486

Morgan, F. P. (2018). Cultural values in clothing: Apotropaic practices. In Dress and personal appearance in late antiquity (pp. 38-64). Leiden: Brill.

Morris, C., \& Peatfield, A. (2002). Feeling through the body. In Thinking through the body (pp. 105-120). Boston, MA: Springer. https://doi.org/10.1007/978-1-4615-0693-5_6

Nadel, S. F. (2013). Malinowski on magic and religion. In Man and Culture (pp. 199-218). London: Routledge. https://doi.org/10.4324/9781315014470

Nasoz, F., Bryce, R. C., Palmer, C. J., \& Rugg, D. J. (2011). A user-centric metadata creation tool for preserving the nation's ecological data. In M. J. Smith \& G. Salvendy (Eds.), Human interface and the management of information: Interacting with information (pp. 122-131). Berlin and Heidelberg: Springer. https://doi.org/10.1007/978-3-642-21793-7_15

Nielsen, J. (1994). Enhancing the explanatory power of usability heuristics. In Proceedings of the SIGCHI conference on human factors in computing systems (pp. 152-158). New York: ACM. https://doi.org/10.1145/191666.191729 
Novel forms of "magical" human-computer interaction within the cyber-physical smart workplace

Nielsen, J., \& Molich, R. (1990). Heuristic evaluation of user interfaces. In Proceedings of the SIGCHI conference on human factors in computing systems (pp. 249-256). New York: ACM. https://doi.org/10.1145/97243.97281

Novak, M. (1991). Liquid architectures in cyberspace. In M. Benedikt (Ed.), Cyberspace: First steps (pp. 225-54). Cambridge, MA: The MIT Press.

Nuño, A. A. (2014). Sympathetic magic and magic-religious mentality from antiquity to the modern world: A longstanding mental structure? Dialogues d'histoire ancienne, 40(1), 147-162. https://doi.org/10.3917/dha.401.0147

Ouellet, H., Romero, M., \& Sawchuk, K. (2017). Promoting intergenerational participation through game creation activities. In Game-based learning across the lifespan. Cham: Springer. https://doi.org/10.1007/978-3-319-41797-4

Pataranutaporn, P., \& Lyle, K. (2018). Toward human-magic interaction: Interfacing biological, tangible, and cultural technology. In International conference on human-computer interaction (pp. 213-221). Cham: Springer. https://doi.org/10.1007/978-3-319-92285-0_30

Philsooph, H. (1971). Primitive magic and mana. Man, 6(2), 182-203. https://doi.org/10.2307/2798261

Polson, P. G., \& Lewis, C. H. (1990). Theory-based design for easily learned interfaces. Human-Computer Interaction, 5(2), 191-220. https://doi.org/10.1207/s15327051hci0502\&3_3

Poslad, S. (2011). Ubiquitous computing: Smart devices, environments and interactions. New York: John Wiley \& Sons.

Poupyrev, I., Nashida, T., Maruyama, S., Rekimoto, J., \& Yamaji, Y. (2004). Lumen: Interactive visual and shape display for calm computing. In ACM SIGGRAPH 2004 Emerging technologies (p. 17). New York: ACM. https://doi.org/10.1145/1186155.1186173

Quiñones, D., \& Rusu, C. (2017). How to develop usability heuristics: A systematic literature review. Computer Standards \& Interfaces, 53, 89-122. https://doi.org/10.1016/j.csi.2017.03.009

Raj, P., \& Raman, A. C. (2017). The Internet of Things: Enabling technologies, platforms, and use cases. Boca Raton: CRC Press. https://doi.org/10.1201/9781315270395

Randles, S. (2013). Material magic: The deliberate concealment of footwear and other clothing. Parergon, 30(2), 109-128. https://doi.org/10.1353/pgn.2013.0117

Remagnino, P., Hagras, H., Monekosso, N., \& Velastin, S. (2005). Ambient intelligence. In P. Remagnino, G. L. Foresti, \& T. Ellis (Eds.), Ambient intelligence (pp. 1-14). New York: Springer. https://doi.org/10.1007/b100343

Renevier, P., \& Nigay, L. (2001). Mobile collaborative augmented reality: The augmented stroll. In Engineering for human-computer interaction (pp. 299-316). Berlin, Heidelberg: Springer. https://doi.org/10.1007/3-540-45348-2_25

Rhodes, C., \& Pitsis, A. (2008). Organization and mimetic excess: Magic, critique, and style. International Studies of Management \& Organization, 38(1), 71-91. https://doi.org/10.2753/IMO0020-8825380104

Rogers, Y. (2004). New theoretical approaches for human-computer interaction. Annual Review of Information Science and Technology, 38(1), 87-143. https://doi.org/10.1002/aris.1440380103

Rohn, J. A. (1993). Usability engineering: Improving customer satisfaction while lowering development costs. Mountain View, CA: SunSoft, Inc.

Rose, D. (2014). Enchanted objects: Innovation, design, and the future of technology. Simon and Schuster.

Sachs, J. D., Benzell, S. G., \& LaGarda, G. (2015). Robots: Curse or Blessing? A Basic Framework. NBER Working Papers Series, Working Paper 21091. Cambridge, MA: National Bureau of Economic Research. https://doi.org/10.3386/w21091

Samani, H. A., Valino Koh, J. T. K., Saadatian, E., \& Polydorou, D. (2012). Towards robotics leadership: An analysis of leadership characteristics and the roles robots will inherit in future human society. In J.-S. Pan, S.-M. Chen, \& N. T. Nguyen (Eds.), Intelligent information and database systems (pp. 158-165). Berlin Heidelberg: Springer. https://doi.org/10.1007/978-3-642-28490-8_17

Schwarz, R. A. (1979). Uncovering the secret vice: Toward an anthropology of clothing and adornment. In J.M. Cordwell \& R.A. Schwarz (Eds.), The fabrics of culture: The anthropology of clothing and adornment 
(pp. 23-45). The Hague: Mouton Publishers.

Senft, G. (1997). Magical conversation on the Trobriand Islands. Anthropos, 369-391.

Sengers, P., Boehner, K., Mateas, M., \& Gay, G. (2008). The disenchantment of affect. Personal and Ubiquitous Computing, 12(5), 347-358. https://doi.org/10.1007/s00779-007-0161-4

Shapiro, A. N. (2014). Software Code as Expanded Narration. Retrieved from http://www.alan-shapiro.com/software-code-as-expanded-narration-by-alan-n-shapiro

Smirnov, A., Kashevnik, A., \& Ponomarev, A. (2015). Multi-level self-organization in cyber-physical-social systems: Smart home cleaning scenario. Procedia CIRP, 30, 329-34. https://doi.org/10.1016/j.procir.2015.02.089

Smith, D. C., Irby, C., Kimball, R., Verplank, B., \& Harslem, E. (1982). Designing the Star user interface. Byte, 7 , 242-282. https://doi.org/10.1145/1500774.1500840

Smith, J. Z. (1995). Trading places. In M. Meyer \& P. Mirecki (Eds.), Ancient magic and ritual power (pp. 13-28). Leiden: E.J. Brill.

Sørensen, J. (2007). A cognitive theory of magic. Lanham: Rowman Altamira.

Sperber, D. (2004). Agency, religion, and magic. Behavioral and Brain Sciences, 27(6), 750-751. https://doi.org/10.1017/S0140525X04430179

Stein, R. L., \& Stein, P. L. (2017). The anthropology of religion, magic, and witchcraft. New York: Routledge. https://doi.org/10.4324/9781315532172

Stoller, P. (1984). Sound in Songhay cultural experience. American Ethnologist, 11(3), 559-570. https://doi.org/10.1525/ae.1984.11.3.02a00090

Subbotsky, E. (2011). The ghost in the machine: Why and how the belief in magic survives in the rational mind. Human Development, 54(3), 126-143. https://doi.org/10.1159/000329129

Tambiah, S. J. (1990). Magic, science and religion and the scope of rationality. Cambridge: Cambridge University Press.

Tambiah, S. J. (1973). Form and meaning of magical acts: A point of view. In R. Horton \& R. Finnegan (Eds.), Modes of thought: Essays on thinking in Western and non-Western societies. London: Faber \& Faber.

Tambiah, S. J. (1968). The magical power of words. Man, 3(2), 175-208. https://doi.org/10.2307/2798500

Twain, M. [S. L. Clemens] (1889). A Yankee at the court of King Arthur. London: Chatto \& Windus.

Wallis, R. J. (2002). The bwili or 'flying tricksters' of Malakula: A critical discussion of recent debates on rock art, ethnography and shamanisms. Journal of the Royal Anthropological Institute, 8(4), 735-760. https://doi.org/10.1111/1467-9655.00131

Wang, Y., Vuran, M. C., Goddard, S. (2008). Cyber-physical systems in industrial process control. ACM Sigbed Review, 5(1). https://doi.org/10.1145/1366283.1366295

Wilson, J. (2010). Essentials of business research: A guide to doing your research project. London: SAGE Publications.

Zusne, L., \& Jones, W. H. (2014). Anomalistic psychology: A study of magical thinking (2nd ed.). New York: Psychology Press. 